\title{
モンテカルロ法応用の室内直接照度の計算 CALCULATION OF DIRECT ILLUMINANCE OF INTERIORS USING MONTE CARLO METHOD
}

\author{
永田忠彦*, 田辺智彦** \\ Tadahiko NAGATA and Tomohiko TANABE
}

\begin{abstract}
The authors at first argue about what the necessary and sufficient condition is with regard to Monte Carlo simulations for the calculation of illuminance of interiors. Although this condition has rarely been definitely argued about, when you devise a new simulation, it is very important to accurately understand what the condition is. After showing the condition, the authors give some newly-devised simulations together with a conventional one, discuss their validity, and compare advantages and disadvantages among them.
\end{abstract}

\section{Keywords : calculation of illuminance, direct illuminance, Monte Carlo method, weighted particle of light \\ 照度計算，直接照度，モンテカルロ法，重みつき光子束}

1.はじめに

従来使用されてきた室内照度計算法の多くは，現今の 多様化した室内照明環境に十分対処できていない。すな わち，室内照明環境の面からいえば，光を発する光源や 照明器具の配光は千差万別であるし，室内周壁面や家具 表面のような光を反射する室内表面の形状や反射特性も また千差万別である。他方，これに対処すべき室内照度 計算法の面からいえば，直接照度については，十分に精 確な計算法が幾つか既に考案されているが，間接照度又 は間接照度を含めた室内照度については，十分に精確な 計算法が確立されているとはいい難い。従来比較的精密 な解法之されている多元連立 1 次方程式を利用する方法 でも, 室内表面の均等拡散性反射を仮定しているので， 常に精確な值が得られるわけではない。

こうした背景のもとに近年，モンテカルロ法を応用し た室内照度の計算が試みられるようになってきた ${ }^{12) 。 ~}$ モンテカルロ法応用の照度計算法は乱数を使用する近似
計算法であるが，複雑な室内照明環境にも十分対処でき る有用な手法であることも知られるようになって来た。 一般に，モンテカルロ法応用の室内照度計算法では，通 常は坒間的に連続的な広がりを持つ光束を, 空間を直進 して室内表面ではシミュレーションの方法に応じた特有 の仕方で反射又は吸収される性質を持つ空間的な広がり を持たない離散型の十分に多くの「光子束」に置き換え て, 光束の室内での伝達を光子束の室内での飛行挙動で シミュレートする方法が採られているい。

このシミュレーションにおいては, 室内表面を十分に 小さな十分に多くの適当数の面皘要素に分割しておき, 光源から発散される光子束の全量を光源から発散される 光束の全量に対応させ，それぞれの光子束については， その重み・飛行方向・室内表面での反射又は吸収の仕方 をそ机ぞれ一様乱数 $R[0,1]$ を用いて確率事象として適 切にシミュレートし，最終的にどこかの面積要素で吸収 されてしまうまで追跡し，その過程で各面積要素に入射
* 福井大学工学部環境設計工学科 教授. 工博

** 福井大学大学院博士前期課程 大学院生
Prof., Dept. of Architecture and Civil Engineering, Faculty of Engineering, Fukui University, Dr. Eng. Graduate Student, Fukui University 
する光子束の量を加算していく。このような計算過程を 光源から発散される全光子束について繰り返すと，結局 各面積要素に入射する光子束の量を求めることができ， その面積要素の照度を求めることができる。ここで用い た $R[0,1]$ という記法は， $R$ が変数で，その変数の亡り 得る値の下限が0で上限が1であることを意味するものと

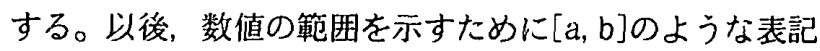
が使われるときには，aが下限でbが上限である。

上記の計算過程では光子束の挙動を確率事象として扱 っているので，各面積要素に入射する光子束の量は当然 に確率事象と見なされている。従って, シミュレーショ ンの方法としては, 『光源から発散される全光子束量に 対する各面積要素に入射する光子束量の比の期待値は, 光源からの全発散光束に対するその面積要素に入射する 光束の比に等しい。』という条件を満たしていなければ ならないし，逆に，その条件が満たされていれば，どの ようなシミュレーションの方法が採られてもその方法は 照度の計算法として通用する。この条件は，自明なこと 亡考えられていたためかどうかは分からないが，従来あ まり強調されていないが，いろいろなシミュレーション を案出する際の理論的根拠として重要である。

本論文では，室内の直接照度に関して，モンテカルロ 法を応用した計算法として通用するシミュレーションの 方法を, 従来普通に採用されていたものも含めて幾つか 示し，それらの長短を比較検討する。間接照度に関して は改めて別稿で論ずることにする。

本論文では各種変量の単位として，面積は $\left(\mathrm{m}^{2}\right)$, 光束 は(1m), 照度は(1x), 光度は(cd), 角度は( $\mathrm{rad})$, 立体角 は(sr)をそれぞれ用いることとする。

\section{2. 基本的な考え方}

受照面上のある点の照度は，その点を含む面積要素へ の入射光束の面積密度之定義することができる。従って， 室内表面のある面積要素 $A_{1}$ に入射する光束 $F_{\mathrm{i}}$ を求めれ ば，その面積要素の照度 $E_{i}$ は次の式(1)のように求める ことができる。

$$
E_{\mathrm{i}}=\frac{F_{\mathrm{i}}}{A_{\mathrm{i}}}
$$

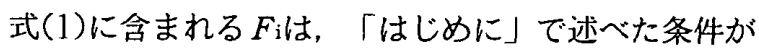
満たされているのであれば，近似的に式(2)のように求め ることができる。ここに，F仙光源からの全発散光束 であり， $B_{\mathrm{i}}$ は各面積要素に入射する光子束の量， $B$ tは 光源から発散される全発散光子束の量である。

$$
F_{\mathrm{i}}=F_{\mathrm{t}} \times \frac{B_{\mathrm{i}}}{B_{\mathrm{t}}}
$$

従って，各面積要素の照度 $E_{\text {i }}$ ，式(1)，（2)から近 似的に式(3)のように求めることができる。

$$
E_{\mathrm{i}}=F_{\mathrm{t}} \times \frac{B_{\mathrm{i}}}{B_{\mathrm{t}}} \times \frac{1}{A_{\mathrm{i}}}
$$

以上の手順を含めて，直接照度の計算手順を示すと次 のようになる。

(1) 室内表面を適当な大きさを持つ適当な個数の面積要 素に分割する。

(2) 各面積要素への入射光子束の初期値を0に設定する。

(3) 光源から発散させる全光子束の個数を決める。

(4) 光源から光子束を発散させる。発散光子束の方向之 重みは，光源の配光に基づいて乱数を使用して適切に 定める。

(5) 室内空間を直進する光子束がどの面積要素に到達す るかを調べ，その光子束の量をその面積要素のそれ以 前の入射光子束量に加算する。

(6) 光源から発散される全ての光子束について(4)(5)を繰 り返す。

(7) 式(3)から各面積要素の照度を求める。

3. 光源から発散する光東のシミュレーション

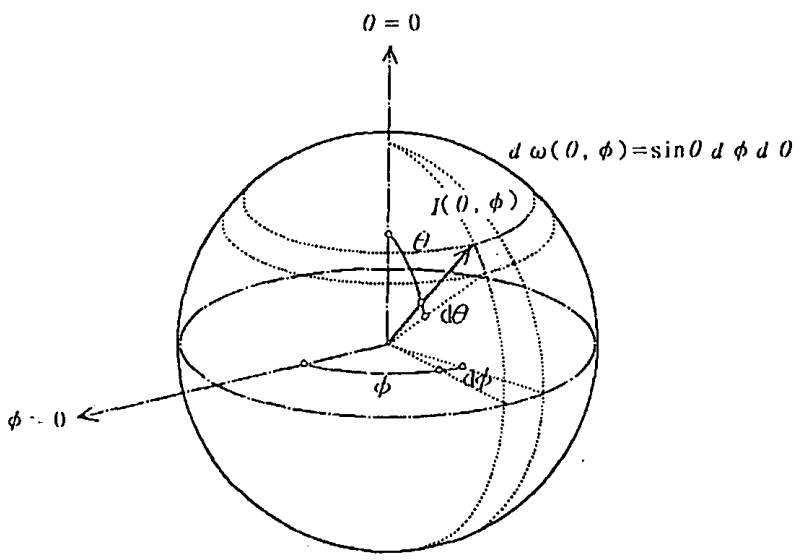

図1．光子束の発散方向と立体角

本稿では, 図1に示すように鉛直角 $\theta[0, \pi]$ と方位角 $\phi[0,2 \pi]$ で定まる方向を $D(\theta, \phi)$ と表し，この光源の $D(\theta, \phi)$ 方向への光度を $I(\theta, \phi)$ と表すことにする。 このとき， $D(\theta, \phi)$ の方向の立体角要素 $d \omega(\theta, \phi)=$ $\sin \theta d \phi d \theta$ の中に発散される光束 $d F(\theta, \phi)$ は，次 の式(4)で表される。

$$
d F(\theta, \phi)=I(\theta, \phi) \sin \theta d \phi d \theta
$$

これは一般には $\theta$ と $\phi$ の両方の関数である。また，この 光源からの全発散光束 $F_{\mathrm{t}}$ は次のように表される。

$$
F_{\mathrm{t}}=\int_{0}^{\pi} d \theta \int_{0}^{2 \pi} I(\theta, \phi) \sin \theta d \phi
$$

また, 光源から $D(\theta, \phi)$ の方向に発散する光子束の 重みを $W(\theta, \phi)$ と表すことにする。

本稿では光子束の発散方向を表すためにも，広く一般 に方向を表すためにも，同じく $\theta$ と中を用いているが， 特に混乱することはないと思われる。 光源から発散される光束を光子束でシミュレートする 
には，光源から発散されるそれぞれの光子束の重みと発 散方向を適切に定めてやればよい。その際には，「はじ めに」に述べた条件が満たされていればよいわけである が，その条件は下記のように言い換えることができる。

条件：『光源から発散される全光子束量に対する光源 から任意の立体角内に発散される光子束量の比の期待值 は, 光源から発散される全光束に対する光源からその立 体角内に発散される光束の比に等しい。』

上記の条件は下式のように表すこともできる。

$\frac{N \cdot P(\theta, \phi) \cdot W(\theta, \phi)}{B_{\mathrm{t}}}=\frac{I(\theta, \phi) \sin \theta d \phi d \theta}{F_{\mathrm{t}}}$

ここに，N は光源から発散される光子束の総数であ

り, $P(\theta, \phi)$ は, 光子束が光源から $D(\theta, \phi)$ の方向の 立体角要素 $d \omega(\theta, \phi)=\sin \theta d \phi d \theta$ の中に発散され る確率である。

各シミュレーションにおいては，独立の 2 個の一様乱 数 $R_{1}[0,1], R_{2}[0,1]$ から光子束の発散方向 $D(\theta, \phi)$ が 定められる。その際, 乱数の組 $\left(R_{1}, R_{2}\right)$ が, $R R_{1}$ が $\left[R_{1}, R_{1}\right.$ $\left.+d R_{1}\right]$ で $R_{2}$ が $\left[R_{2}, R_{2}+d R_{2}\right]$ の領域要素の中に選ばれる 確率は $d R_{1} d R_{2}$ であるから, この領域要素に対応して定 められる $D(\theta, \phi)$ の方向の立体角要素 $d \omega(\theta, \phi)$ の中 に光子束が発散される確率 $P(\theta, \phi)$ は当然 $d R 1 d R 2$ に等 しい。従って, $P(\theta, \phi)$ は式(7)から求めることができ, それを式(6)に代入すれば $W(\theta, \phi)$ を定めることが可 能亡なる。 $\left|\frac{\partial\left(R_{1}, R_{2}\right)}{\partial(\theta, \phi)}\right|$ は $R_{1}, R_{2} の \theta ， \phi に$ 関する Jacobianの絶対值である。

$$
\begin{aligned}
P(\theta, \phi) & =d R_{1} d R_{2} \\
& =\left|\frac{\partial\left(R_{1}, R_{2}\right)}{\partial(\theta, \phi)}\right| d \theta d \phi
\end{aligned}
$$

さて，シミュレーションの方法としては，上記の条件 を満たしていればどのようなものであっても構わないが， 下記の(1) (6)は上記の条件を満たすものの例である。こ のうち(1)従来も普通に採用されていた方法である。

(1) 各光子束の重みを発散方向の如何に関わらず一様に 定数 C (通常は $\mathrm{C}=1$ として差し支えない。) と仮定し， 各光子束の発散方向については，式(8)によって一様乱 数 $R 1[0,1]$ から $\theta$ を定め; 次に式(9)によって別の一 様乱数 $R_{2}[0,1]$ から $\phi$ を定める。

$$
\begin{aligned}
& R_{1}=\frac{\int_{0}^{\theta} d \theta \int_{0}^{2 \pi} I(\theta, \phi) \sin \theta d \phi}{\int_{0}^{\pi} d \theta \int_{0}^{2 \pi} I(\theta, \phi) \sin \theta d \phi} \\
& R_{2}=\frac{\int_{0}^{\phi} I(\theta, \phi) d \phi}{\int_{0}^{2 \pi} I(\theta, \phi) d \phi}
\end{aligned}
$$

式(8)，（9）を用いる根拠は次のように示すことがで きる。すなわち, 光源から鈶直角 $\theta$ が $[0, \theta]$ の範囲に 発散される光束の光源から発散される全光束に対する 比 $P(\theta)$ は式(10)のように表されるから，これを一様 乱数 $R$ 1 対応させる。

また，光源から鉛直角 $\theta$ が $[\theta, \theta+d \theta]$ 範囲で 方位角 $\phi$ が $[0, \phi]$ の範囲に発散される光束の, 鉛直角 $\theta$ が $[\theta, \theta+d \theta]$ 範囲全体に発散される光束に対 する比 $Q(\phi)$ は式(11)のように表されるから，これを 一様乱数 $R 2$ と対応させる。

$$
\begin{aligned}
P(\theta) & =\frac{\int_{0}^{\theta} d \theta \int_{0}^{2 \pi} I(\theta, \phi) \sin \theta d \phi}{\int_{0}^{\pi} d \theta \int_{0}^{2 \pi} I(\theta, \phi) \sin \theta d \phi} \\
Q(\phi) & =\frac{d \theta \int_{0}^{\phi} I(\theta, \phi) \sin \theta d \phi}{d \theta \int_{0}^{2 \pi} I(\theta, \phi) \sin \theta d \phi} \\
& =\frac{\int_{0}^{\phi} I(\theta, \phi) d \phi}{\int_{0}^{2 \pi} I(\theta, \phi) d \phi}
\end{aligned}
$$

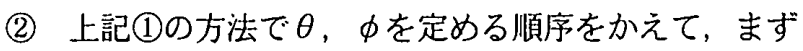
方位角 $\phi$ を定め, 次に鉛直角 $\theta$ を定めてもよいことは 当然である。

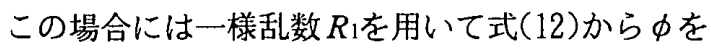
定め, 次に別の一様乱数 $R 2$ を用いて式(13)加 $\theta$ を 定めればよい。

$$
\begin{aligned}
& R_{1}=\frac{\int_{0}^{\phi} d \phi \int_{0}^{\pi} I(\theta, \phi) \sin \theta d \theta}{\int_{0}^{2 \pi} d \phi \int_{0}^{\pi} I(\theta, \phi) \sin \theta d \theta} \\
& R_{2}=\frac{\int_{0}^{\theta} I(\theta, \phi) \sin \theta d \theta}{\int_{0}^{\pi} I(\theta, \phi) \sin \theta d \theta}
\end{aligned}
$$

（3）上記(1)(2)の方法で，光源の配光が複雑な場合には， その配光を表す関数が複雑なために，光子束の発散方 向 $D(\theta, \phi)$ を正確に求められないことも考えられる。 その場合には何らかの近似的な解法によって求めなけ ればならない。その方法も当然いろいろなものが考え られるが，上記(1) $\theta$ を求める近似的な解法の一例之 して次のようなものが考えられる。

はじめに鉿直角 $\theta[0, \pi]$ を必ずしも等間隔ではない 十分多数の $M$ 個の微小区間 $\left[\theta_{\mathrm{m}-1}, \theta_{\mathbb{q}}\right](1 \leqq m \leqq M$, $\left.\theta_{0}=0\right)$ に分割し, 式(10)の関数 $P(\theta)$ を用いて $P\left(\theta_{\text {巴 }}\right)$ を求めておき，一様乱数 $R 1[0,1]$ を用いて式(14)また

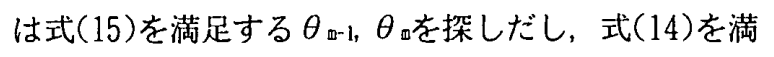


足すれば式(16)によって，式(15)を满足すれば 1 次補 間によって式(17)のように $\theta$ を定める。

$$
\begin{gathered}
R_{1}=P\left(\theta_{\mathbb{\varpi}}\right) \\
P\left(\theta_{\mathbb{m}-1}\right)<R_{1}<P\left(\theta_{\mathbb{m}}\right) \\
\theta=\theta_{\mathbb{m}} \\
\theta=\theta_{\mathbb{m}-1}+\frac{R_{1}-P\left(\theta_{\mathbb{m}-1}\right)}{P\left(\theta_{\mathbb{\varpi}}\right)-P\left(\theta_{\mathbb{m}-1}\right)}\left(\theta_{\mathbb{m}}-\theta_{\mathbb{m}-1}\right)
\end{gathered}
$$

この方法では，分割数 $M$ が小さいと誤差が大きく なるので，十分に大きい $M$ を採用する必要がある。 他の式(9)(12)(13)加 $\theta ， \phi$ を正確に求められない場 合にも同様の方法で定めることができる。

(4) 光子束の発散方向を鉛直角 $\theta$, 方位角 $\phi$ のどちらに ついても一様の密度となるように定める。つまり，次 の式(18)(19)のように一様乱数 $R_{1}[0,1] ， R_{2}[0,1]$ を

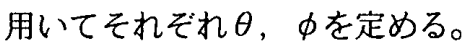

$$
\begin{aligned}
& R_{1}=\theta / \pi \\
& R_{2}=\phi / 2 \pi
\end{aligned}
$$

この場合には発散させる光子束の重み $W(\theta, \phi) を$ 式(20)のように定めて上記の条件を満たすようにすれ ばよい。つまり, 光子束の重みを $D(\theta, \phi)$ 方向の 立体角要素の中に発散される光束 $d F(\theta, \phi)$ に比例す るように定めればよい( $\mathrm{C}$ : 任意定数 $) 。$

$$
W(\theta, \phi)=\mathrm{C} \cdot I(\theta, \phi) \sin \theta
$$

(5) 光子束の発散方向を立体角に関して一様な密度とな るように定める。つまり，次の式(21)(22)のように， 一様乱数 $R_{1}[0,1] ， R_{2}[0,1]$ を用いてそれぞれ $\theta ， \phi$ を定める。

$$
\begin{aligned}
R_{1} & =\frac{\int_{0}^{\theta} d \theta \int_{0}^{2 \pi} \sin \theta d \phi}{\int_{0}^{\pi} d \theta \int_{0}^{2 \pi} \sin \theta d \phi} \\
& =\frac{\int_{0}^{\theta} \sin \theta d \theta}{2} \\
R_{2} & =\frac{d \theta \int_{0}^{\phi} \sin \theta d \phi}{d \theta \int_{0}^{2 \pi} \sin \theta d \phi} \\
& =\phi / 2 \pi
\end{aligned}
$$

この場合には，発散させる光子束の重み $W(\theta, \phi)$ を式(23)のように定めて上記の条件を満たすようにす ればよい。つまり, 光子束の重みを $D(\theta, \phi)$ の方向 の光度 $I(\theta, \phi)(\mathrm{cd})$ に比例するように定め机ばよい ( $\mathrm{C}$ : 任意定数)。

$$
W(\theta, \phi)=\mathrm{C} \cdot I(\theta, \phi)
$$

（6) 上記(1)(2)の方法の長所は，光束が多く発散される方 面には多くの，逆に光束が少なく発散される方面には 少しの, それぞれ同等の重みを持つ光子束を発散させ るので，現実の光束の挙動に即した素直な方法と考え られることであるが, 最大の短所は, 光源の配光が複 雑な場合に $\theta ， \phi$ を正確に求められないことである。 一方, 上記(4)(5)の方法の長所は, 光子束の重みを調整 することで光源の配光が複雑な場合にも, 光子束の発 散方向を容易に定められることであるが，短所は，光 束のあまり発散されない方面には重みの小さい光子束 を発散させることになり, 光源の配光に大きな偏りが ある場合には，照度の計算結果に与える影響が小さい 光子束に対して屯影㽡度の大きい光子束と同等の計算 時間を費やすことである。両者の長所短所はちょうど 逆になっているので，両者の長所だけを組み合わせた 方法も当然考えられてよい。一例として，上記(1)の方 法を基䃈にして，それが光源の配光が複雑な場合にも 容易に対応できるように，上記(4)(5)の方法を取り入れ た方法を次に示す。

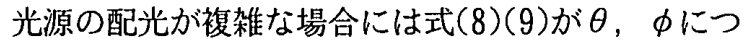
いて解けないことが考えられる。その場合には，式(8) (9)の中の光度 $I(\theta, \phi)$ を, 式(8)(9)が $\theta, \phi に つ い$ て解けるような比較的に単純な関数 $I^{\prime}(\theta, \phi)$ で近似 して代用し, 式(24)(25)加(1)方法之同様に一様乱 数を対応させて $\theta ， \phi$ を定める。その方向に発散させ る光子束の重みは上記の条件を満たすように式(26)の ように定める( $\mathrm{C}$ :任意定数)。

$$
\begin{aligned}
& R_{1}=\frac{\int_{0}^{\theta} d \theta \int_{0}^{2 \pi} I^{\prime}(\theta, \phi) \sin \theta d \phi}{\int_{0}^{\pi} d \theta \int_{0}^{2 \pi} I^{\prime}(\theta, \phi) \sin \theta d \phi} \\
& R_{2}=\frac{\int_{0}^{\phi} I^{\prime}(\theta, \phi) d \phi}{\int_{0}^{2 \pi} I^{\prime}(\theta, \phi) d \phi} \\
& W(\theta, \phi)=\mathrm{C} \cdot \frac{I(\theta, \phi)}{I^{(}(\theta, \phi)}
\end{aligned}
$$

\section{4. 計算結果の比較}

シミュレーションの方法が異なったり, 同じ方法であ っても使用する乱数が巽なれば当然照度の計算結果は異 なる。本研究では, 上記の(2)(3)の方法は(1)の方法と理論 的な違いがないので，(1)〜(6)のうちから(1)(4)(5)の方法を 取り上げて，下記の条件の下で室内の直接照度の計算を 行い，それらの計算結果を比較検討し，各方法の妥当性 及びそれらの長短を検討してみた。 


\section{4、1、計算例における仮定}

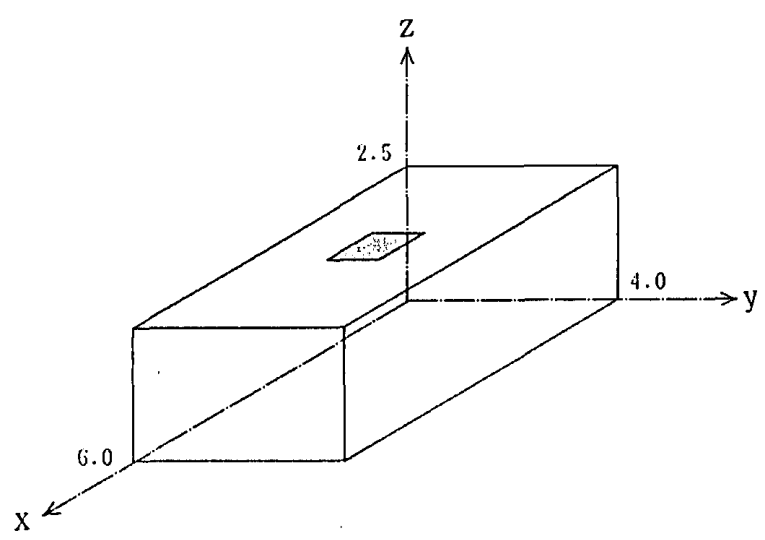

図2、計算に使用した室内空間

モンテカルロ法を応用した室内照度の計算法は，「は じめに」で述べたように, 複雑な室内照明環境への対応 を期待される手法であるが，本稿では，上記の条件を満 足するいろいろな方法の妥当性を検討することを目的の 1つとしているので，実行プログラムの構成や計算時間 などの利便性を考えて次のような比較的に単純な室内照 明環境を仮定した。

室内空間は，図2のような $4.0 \times 6.0 \times 2.5(\mathrm{~m})$ の直方体形 の中空のものを仮定した。この室内空間に図2のように床 面の一隅を原点とするxyz座標系を設定する。この室内表 面を $\mathrm{x}$ 軸 $(0 \leqq x \leqq 6.0) ， y$ 軸 $(0 \leqq y \leqq 4.0) ， z$ 軸 $(0 \leqq z \leqq 2.5)$ をそれぞれ $24,16,10$ 等分し， $0.25 \times 0.25(\mathrm{~m})$ の正方形の面 積要素に分割する。

光源は天井の中央部に $1.0 \times 1.0(\mathrm{~m})$ の正方形の面光源を 仮定した。この光源を $0.01 \times 0.01(\mathrm{~m})$ の 1 万個の面積要素 に分割し，その各面積要素の中央よりそれぞれ同数の光 子束を発散させる。光源の配光特性は全面積要素を通じ て一様と仮定し，次のような光源 I， II の 2 通りを仮定 した。なお，鉛直下方を $\theta=0$ とする。光源 II の配光はか なり非現実的であるが，各シミュレーションの妥当性を 検討するために敢えて仮定してみた。光源 I， II ともに 全発散光束を $20,000(1 \mathrm{~m})$ (各面積要素では $2(1 \mathrm{~m})$ ), 発散光 子束数を 50 万個之 500 万個(各面積要素では 50 個, 500 個) の 2 通りの場合を計算した。

- 光源 I の配光 $(I(0)=2 / \pi(\mathrm{cd}))$

$$
I(\theta)= \begin{cases}I(0) \cos \theta & (0 \leqq \theta \leqq \pi / 2) \\ 0 & (\pi / 2<\theta \leqq \pi)\end{cases}
$$

- 光源 II の配光 $(I(0)=6 /(5 \pi)(\mathrm{cd}))$

$$
I(\theta)= \begin{cases}I(0)(1+\sin \theta) \cos \theta & (0 \leqq \theta \leqq \pi / 2) \\ 0 & (\pi / 2<\theta \leqq \pi)\end{cases}
$$

\section{2. 計算結果の比較}

前記の仮定に基づいて行った前記(1)(4)(5)のシミュレー
ションによる床面直接照度の計算結果を図3〜図6に示す。 図中の i は図2の原点から床面長辺方向にそって数えた床 面面積要素の番号, j は短辺方向にそって数えた床面面 積要素の番号である。これらの図では， $\mathrm{j}=4$ の列と $\mathrm{j}=8$ の 列に沿った照度の分布が示されている。

光源 I の場合は, 均一輝度均等拡散性面光源であるか ら，立体角投射率を用いて直接照度を理論的に求めるこ とができる。その理論値と比較することでモンテカルロ 法を応用した計算法の妥当性を検討することができる。 図3から分かるように，発散光子束数が50万個の場合には 多少のばらつきはあるものの理論值と比較して，まずま ずの程良い値を示している。発散光子束数を 500 万個に增 すと，図4のように非常にばらつきが小さくなり，ほぼ理 論値に等しくなっている。また, 計算に要した時間も各 方法の間にほとんど差はなかった。この計算結果を見る 限り，(1)(4)(5の方法は何れも妥当なものとしてよく，ま た，これらの間に特に優劣を認めることはできない。

光源 II の場合にも，精度や計算時間の面からみて，光 源 I の場合亡同様に，(1)(4)(5)の方法の間に特に優劣を認 めることはできない。

光源 II場合には，(1)の方法でシミュレートする場合 に, 式(8)かisin $\theta$ の3次式になるので， $\theta$ を代数的に求め ることが可能であったが, 代数的に求めることが不可能 な場合を想定して，試みに(3)の方法でも計算をしてみた。 その結果, ここでは計算についての詳細は示さないが(3) の方法で(1)方法と同程度の精度を持つと思われる計算 結果を得るためには, 分割数 $M$ を十分に大きくする必 要があり，(1)りもかなり長い計算時間を要することが 分かった。(1)の代用として(3)を用いることはあまり賢明 とはいえないようである。

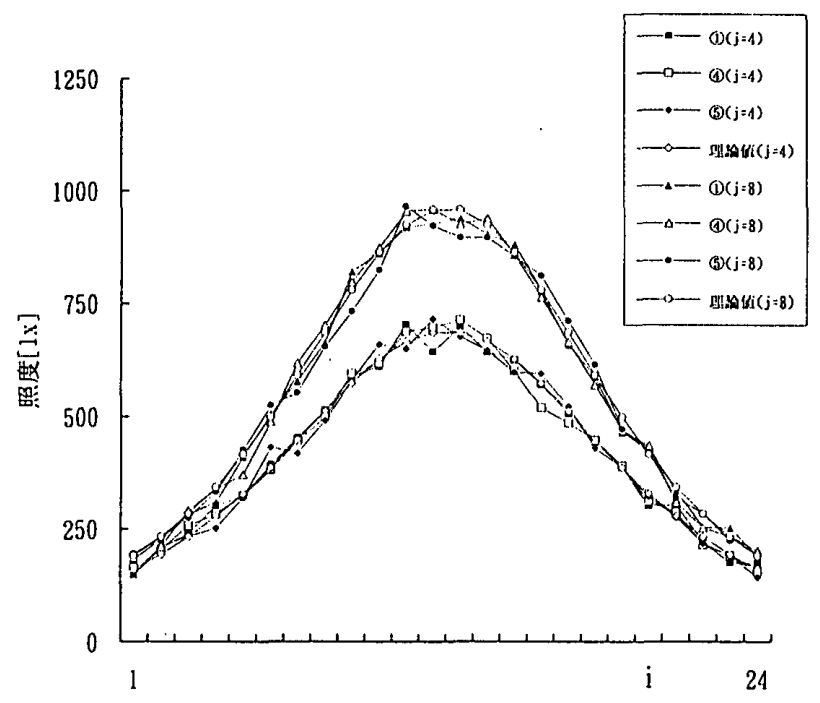

図3．照度分布の計算結果(1) （光源： I, 発散光子束数 : 50 万個） 


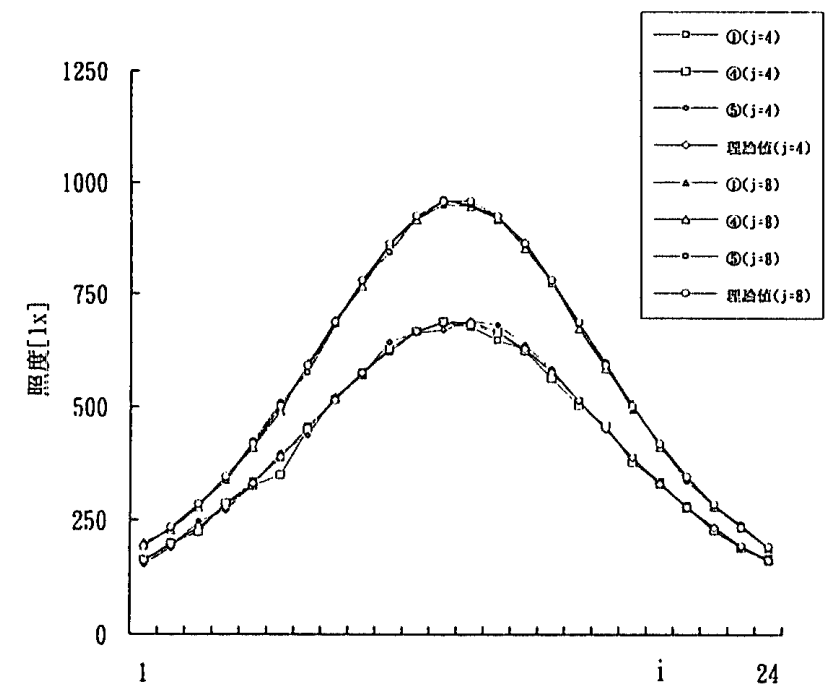

図4. 照度分布の計算結果(2)

（光源：I， 発散光子束数 : 500 万個）

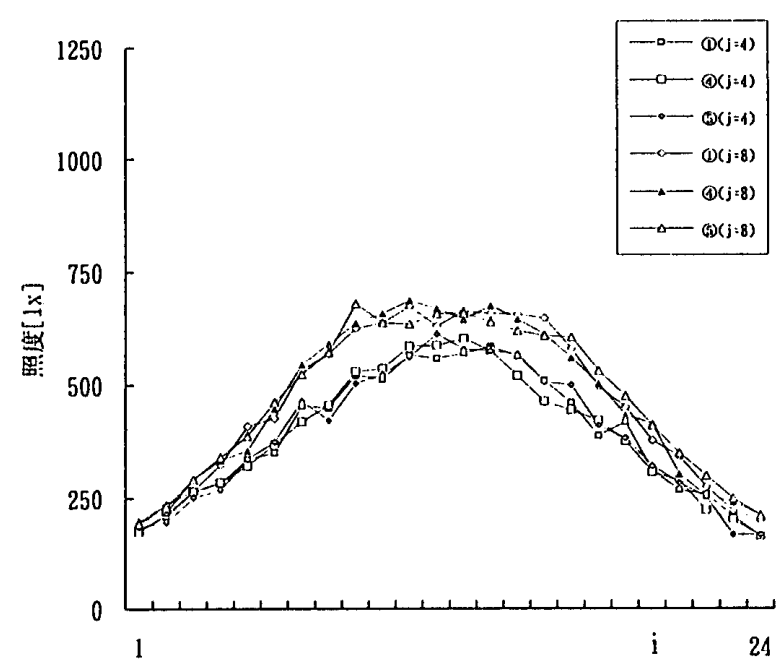

図5. 照度分布の計算結果 (3)

（光源：II，発散光子束数 : 50 万個）

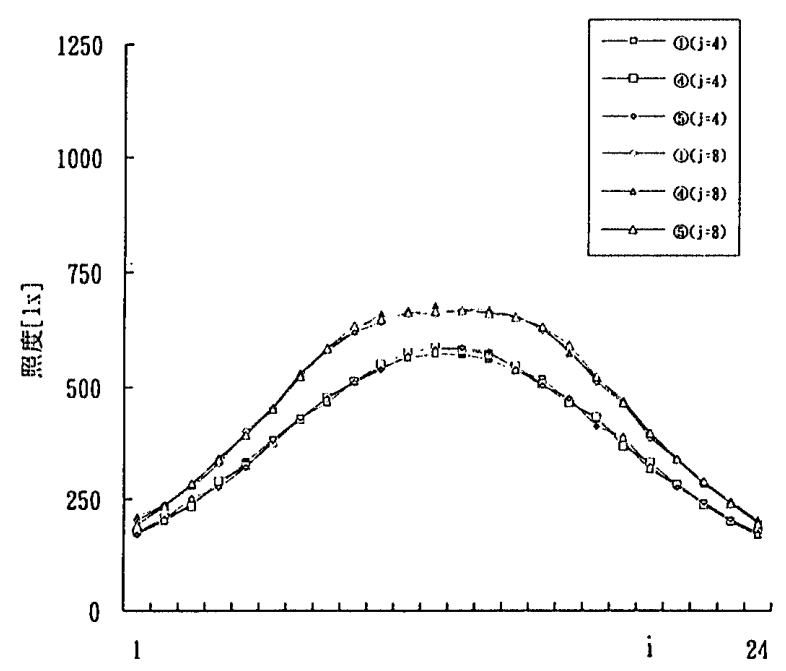

図6. 照度分布の計算結果(4)

（光源：II， 発散光子束数 : 500 万個）

\section{5.おわりに}

均一輝度均等抬散性面光源に対して(1)(4)(5)の方法によ る直接照度の計算結果が理論値と非常によく一致してい ることから(1)(4)(5の各方法の妥当性が確認されたものと してよい。このことはまた，上記で示した条件を満たす シミュレーションの方法であれば，上記で示したもの以 外のどのようなものであっても構わないことを改めて示 唆しているものとも考えられる。

本稿では，(6)の方法による計算結果を特には示してい ないが，実は，(4)(5の方法は(6)の応用例と考えることが できる。つまり, (4)(5)の方法では $I(\theta, \phi)$ の近似とし て代用するI $I^{\prime}(\theta ， \phi)$ をそれぞれ式(27)(28)のようにし た場合であると烤えることができる。

$$
\begin{aligned}
& I^{\prime}(\theta, \phi)=\frac{1}{\sin \theta} \\
& I^{\prime}(\theta, \phi)=1
\end{aligned}
$$

このことは，式(27)(28)を(6)の式(24)(25)(26)に代入 して，それぞれ式(18)(19)(20)，式(21)(22)(23)と比較す ることにより容易に確認することができる。

(4)(5)を(6)の応用例としてみた場合に，式(27)(28)から 明らかなように $I^{\prime}(\theta, \phi)$ は光源の配光を近似したもの ではない。それにも関わらず，(4)(5)の方法による直接照 度の計算結果は(1)の方法と変わらずかなり精確な照度値 を得ることができる。このことは，(6)の方法の妥当性を 示すものであることは勿論のこと， $I^{\prime}(\theta, \phi)$ は, 光源 の配光を非常によく近似できていればそれに越したこと はないが，配光を大雑把に近似している程度で十分であ ることを示すものである。しかしいくら大雑把とはいっ

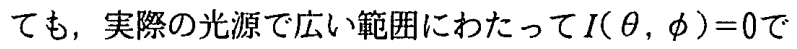

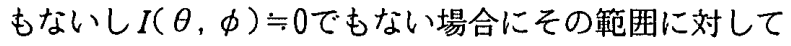
$I^{\prime}(\theta, \phi)=0$ 用いるようなことをしてはならない。も しそのようなことをすると，その方面には光子束が全く 発散されなくなってしまい，「光源から発散する光束の シミュレーション」で述べた条件に反するからである。 また，広い範囲にわたって $I(\theta, \phi)=0$ となっている場 合に，その範囲に対して $I^{\prime}(\theta, \phi)>0$ とすることも好ま しいことではない。

以上のように各方法には長短があるので，特定の方法 に固執することなく，室内の照明環境に応じて適当な方 法を選択あるいは考案すればよいと思われる。

\section{参考文献 \\ 1）長田正蒰：モンテカルロシミュレーションによる凹開面室内空 間の照度分布計算，照明学会誌， $72-10 ， p p .596-601 ， 1988$ \\ 2) P. R. Tregenza : The Monte Carlo Kethod in lighting calcula- tions, Light. Res. \& Tech. , 15-4, pp. 163-170, 1983}

（1995年 9 月 10 日原稿受理，1995年11月20日採用決定） 